\title{
Influence of smart education on characteristics of urban lands' transport systems
}

\author{
Irina Makarova $^{1 *}$, Polina B uyvol ${ }^{1}$, Larisa Fatikhova ${ }^{1}$, and Gleb Parsin ${ }^{1}$ \\ ${ }^{1} \mathrm{~K}$ azan Federal U niversity, 423812 Naberezhnye Chelny, Russia
}

\begin{abstract}
Intelligent well-educated Smart People are the key element of Smart City devel opment. Different technologies are implemented to devel op the residents' intellectual added value, including Smart Education. The introduction of progressive teaching methods can have a synergistic effect, increasing the quality of processes in other systems of Smart Cities. Since the second most common type of correspondence is the trip to education, the hypothesis of a possibility to decrease transport loads on the city roads caused by the widespread introduction of progressive methods of $\mathrm{E}$ Learning and Blended Learning was suggested. The proposed hypothesis was tested and confirmed by the results of simulation.
\end{abstract}

\section{Introduction}

In the field of architecture and urban science, in recent years, more and more attention has been paid to the emergence of "Smart Cities", "Future Cities" and information technologies substituted by smart technologies [17]. The term "smart technology" has appeared about 40 years ago, but only recent development of information and communication technologies has reached a point allowing to build super-complex systems, such as Smart City.

The term "Smart City" is determined in different ways in different sources. In the research of Gabrys [3], it is characterized as a city space equipped with an automated infrastructure, digital sensors' network and ubiquitously used computers that provide additional interaction via mobile devices that collect and analyze Big Data of urban processes in real time. According to research of Thrift [16], Smart City is an urban environment managed by coded devices and infrastructure, structured and maintained strictly in an algorithmic sequence, "a code using data as a fuel". In some ways, "smart cities" are cities that "think for us", with some ability of self-learning and transforming [1].

The main goal of the development of Smart City idea is to create a sustainable model of urban development and preserve the quality of their citizens' life [7]. Smart City combines a variety of technologies to reduce the negative impact on environment, thus providing more comfortable living environment. However, the fulfillment of this task implies in not only the introduction and usage of technical and technological solutions. Organizational actions at the level of governmental legislative acts and resolutions, as well as the whole society, are necessary and important. Therefore, the creation of Smart City is an interdisciplinary task,

* Corresponding author: kamIVM @ mail.ru 
uniting city officials, innovative suppliers, international political structures, scientists and the organization of civil society itself [2].

\section{Theory: Main Directions of Smart Cities Development}

Sustainable urban development, improving the life quality and safety of the population, as well as the introduction of energy efficient technologies are carried out in the following key areas: Smart Economy, Smart Mobility, Smart Governance, Smart Environment, Smart Living and Smart People [5]. The European Union (EU) is constantly making efforts to develop such strategies for the development of urbanized territories, which will allow them to become a Smart City [14]. This means that the transformation of cities into a Smart City should be understood as a sequence of processes. However, many changes are needed so that cities become more efficient, attractive, inclusive and competitive. These changes relate not only to the way how cities look, but they also require cities, businesses, residents and scientists think and work together, heading the same direction [8] (Fig. 1).

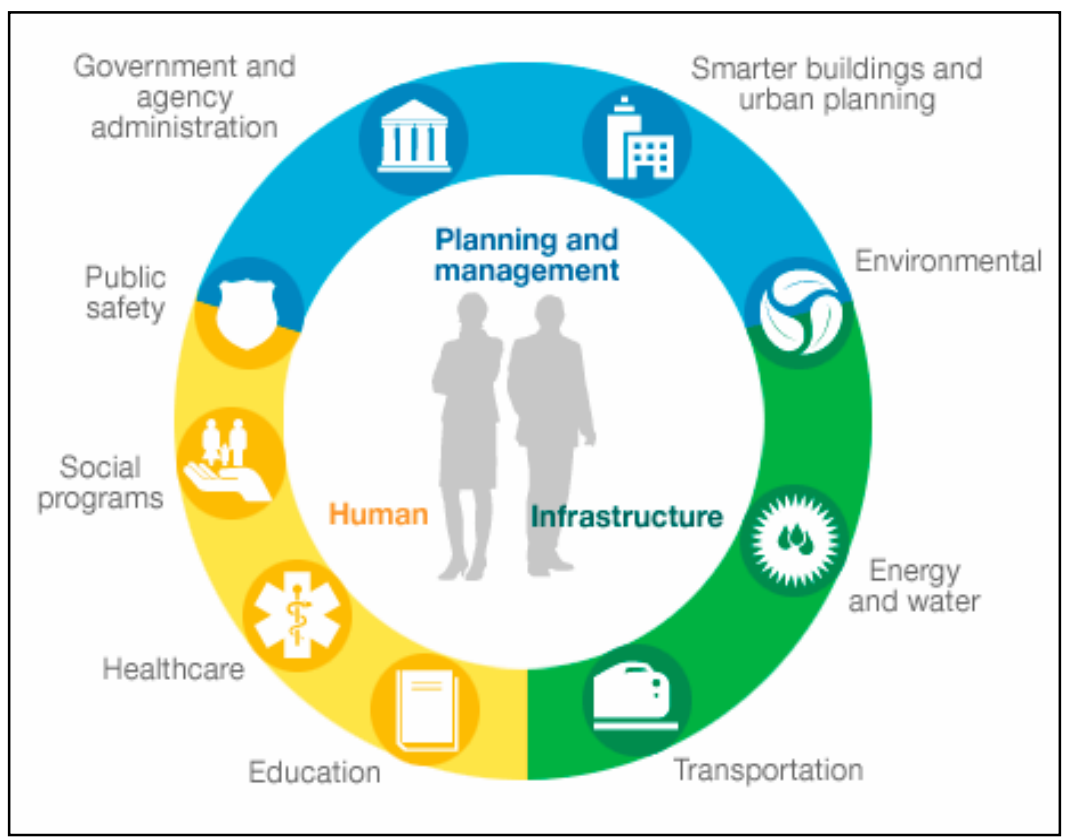

Fig. 1. Smart City Initiative (IBM, 2008) [4].

To ensure dynamic interaction, the following technologies are used:

- Smart Grids - intelligent power transmission systems from a producer to a consumer.

- DC microgrids - solar panels storage.

- "Smart home" - an intelligent home control system providing automatic and consistent operation of all life support and security systems.

- Sustainable mobility (E-mobility) - a pro-ecological initiative that will help to reduce air pollution and promote alternative energy sources (electric transport, non-motorized modes of transport).

- Big (Open) Data + Internet of Things.

In addition, cities should generate a virtual space of interaction between citizens, the private sector and government that promotes an inclusive Information Society using the Internet as well as Information and Communication technologies (ICT) to create an advanced society model that contributes to sustainable economic and social development of cities based 
on ICT. It is important that cities strive to integrate an intellectual added value into their economies and to develop knowledge-based services, as well as to provide access to this knowledge and to universal, systematic, effective ICT that can attract and retain talents [15].

People (their needs, desires, decisions, knowledge, skills) are the basis of all processes taking place in the city. That is why one of the key elements of Smart City development are intelligent well-educated Smart People.

\subsection{Smart Education}

Accelerating digitization of modern society causes the tendency of replacing the "traditional" electronic approach by new "Smart Education" philosophy. Despite the fact that Smart Education is being discussed since 2009, it is currently impossible to talk about an integrated, already formed paradigm due to the so-called second digital divide. It is more about individual solutions and technologies in the field of education. The main distinguishing feature between "Digital City" and "Smart city" are "Smart People".

"Smart" is a property that allows instantly adapting an object or process to environmental changes, and it is becoming more and more actual in modern social development, especially in education.

There is an international standard ISO 37120: 2014 for Smart City, defined by the International Organization for Standardization so that cities can measure and compare their effectiveness and learn "best practices" from each other in terms of infrastructure, management, economy and education indicators [6]. The concept of Smart City assumes a special kind of a "smart citizen". It is an active citizen, who must be educated enough to take part in self-optimizing urban processes. To what extent the city's population is "smart" can be assessed by the level of qualifications and education of residents, as well as the degree of their social activity and the ability to open to the outside world. The factors that characterize the level of education development in Smart City include:

1. Education and training:

- number of residents with bachelor or/and master degree;

- priority areas of educational programs;

- correspondence of the main areas of educational programs to the needs of economics.

2. E-Learning:

- plans for development of digital technologies in classrooms;

- the use of ICT in education;

- implementation of e-learning programs;

- life-long learning.

3. Human resources:

- cooperation between companies, scientific and training centers;

- training of specialists who will be able to solve real production problems taking into account the factors of sustainable urban development [15].

Universities and research centers play a key role in the innovation ecosystem. They are not only a source for the creation of new enterprises, but also bear responsibility for the development of leaders who will be able to organize the interaction of educational institutions, business and government. Universities generate knowledge for the enterprises of the city and serve as a meeting point for educational and scientific centers, students and the world of business. Therefore, it is important that cities strive to develop cooperation between enterprises, educational and scientific centers, thereby contributing to economic and social development. 


\subsection{Sustainable mobility}

Despite the growing level of urban mobility around the world, access to places, activities and services is becoming increasingly difficult. Because of cities growth, the distances between points generating and attracting the passenger flows, increase. This leads to a bigger dependence on individual vehicles. Consequently, widespread traffic congestion and jams have become the norm in many cities nowadays, negatively affecting the population (environmental pollution, noise, stress and road accidents).

The solution can be the implementation of E-mobility concept, which implies two ways: the transition to sustainable modes of transport (public, non-motorized modes of transport, electric transport) and minimizing the number of residents' trips. Addressing the issue of population mobility calls for a paradigm change in urban planning, the promotion of compact cities as a way to increase accessibility and reduce the need for mobility in general. Since the goal of mobility is to gain access to places of employment, goods and services, urban planning should be focused on the needs of city residents in order to reduce distances between places of residence and functional endpoints. Only in this case, it is possible to ensure the economic and ecological feasibility of the decisions made in the field of population mobility. Thus, city residents should be able to satisfy their needs, using as few trips as possible.

One of the most effective way to reduce the number of trips is the development of new communication technologies. Then, some kinds of trips can be replaced by a non-travel activity, for example internet shopping, remote working or teleconferencing.

\section{Methods: From E-Learning to Smart Education}

Rapid development of E-learning was mainly caused by modern achievements in the field of educational technologies, mass media and communication and wide implementation of a variety of technical means. In contrast to traditional education, E-learning develops the creative thinking and independence of the trainee, as well as the possibility to study in an individual pace from any convenient place at any convenient time. At the same time, students feel obvious disadvantages:

- lack of full-time communication with the teacher;

- the need for constant access to information sources;

- insufficient opportunity to acquire practical skills.

From the point of view of teachers E-Learning has following disadvantages:

- the need for regular qualitative updating of educational content;

- lack of possibility to monitor educational process constantly;

- the problem of user identification.

The specified disadvantages are connected with the fact that, speaking about E-learning, emphasis was placed generally on technologies: modules with educational content, providing feedback to teachers and students, and automation of administrative tasks. Smart Education is the further development of the E-Learning concept, which is the central, system-forming element of the digital society along with such components as the economy of knowledge, Industry 4.0 (digital production), e-culture, e-health, e-government, e-science.

The main principles of Smart Education include:

- Free access to knowledge based on the E-learning system.

- Individual approach to the training of each student in the framework of the modular principle according to the list of competencies chosen by the trainee.

- Movement of knowledge objects from teacher to student and back, as well as mutual training of the group.

The concept of Smart Education is aimed at the creation of Smart People. Therefore, the quality of training, the correspondence of educational system to the current needs of 
economics and the ways of how people implement their knowledge and skills are very important.

Today, neither traditional education nor E-learning methods allow the full use of advanced educational technologies to improve the education quality. This is due to the fact that the applied teaching methods (lectures, practical exercises, seminars, tests) do not allow preparing specialists for production activities at the concrete enterprises. In addition, there is the problem of objectivity in assessing the education quality. An effective solution is the usage of Blended Learning [10], which unites in itself advantages of both methods, and also allows the use of progressive educational technologies (modeling, virtual reality application, gaming education, etc.) intensifying the process of studying.

Blended Learning implies that $30-79 \%$ of the course is implemented online, and difficult aspects are studied in the classroom with the teacher. Most researchers note that Blended Learning is a modern, universal way of education, focused on the individual needs of students. The fundamental difference between Blended Learning and the traditional education system is the combination of organizational learning forms in the real and virtual campus of the university and a combination of traditional teaching methods with E-learning technologies. At the same time, the process of combining technologies can take place both at the level of a separate course, discipline, and at the level of the educational program as a whole.

Blended Learning, in addition to achieving the main goal of Smart Education - the creation of Smart People by improving the education quality, can have an additional positive effect. The technology of Smart Education is designed to make the "effect of presence" of the learner, and also allows entering into a greater number of "horizontal" communication links and, in general, significantly speeds up and simplifies the process of communication between participants in the educational process without the need to move the learner in space. Since the second most common type of correspondence are study trips, the widespread of Elearning and Blended Learning technologies can also reduce traffic loads on the street-road network (SRN) during peak hours.

\section{Results and Discussions: Prospects for Reducing the Transport Load in Naberezhnye Chelny City}

To assess the operation of transport system in case of changing certain parameters, simulation methods are usually used. Analysis of the possibilities and purpose of existing software for transport modeling has showed that to solve the problem of forecasting traffic loads on urban areas, it is better to use a specialized package of macrosimulation PTV VISUM [9,11].

One of the main factors influencing the characteristics of transport systems is the transport demand of the population, which is the basis of origin-destination matrices. Creation of the origin-destination matrix and distribution of traffic flows allows using the city's SRN models and model of transportation demand that take into account parameters of the real system. Then, as a result of the computer simulation, levels of loads on SRN segments are calculated.

The problem of congested roads is actual for Naberezhnye Chelny, despite the fact that it was designed taking into account the possible growth of the number of both individual and passenger transport on the roads. This is due to the fact that the transport-planning framework of the city is made up of longitudinal highways connecting the residential areas of the city and merging into one on Naberezhnochelninsky Avenue. Viewing the fact that a significant part of the trips during peak hours correspond to labor and education, a hypothesis about the possibility to reduce the transport loads through transition from the traditional educational forms to the Blended Learning has been put forward. Fig. 2 shows a map of the city with the locations of colleges and institutions of higher education. 


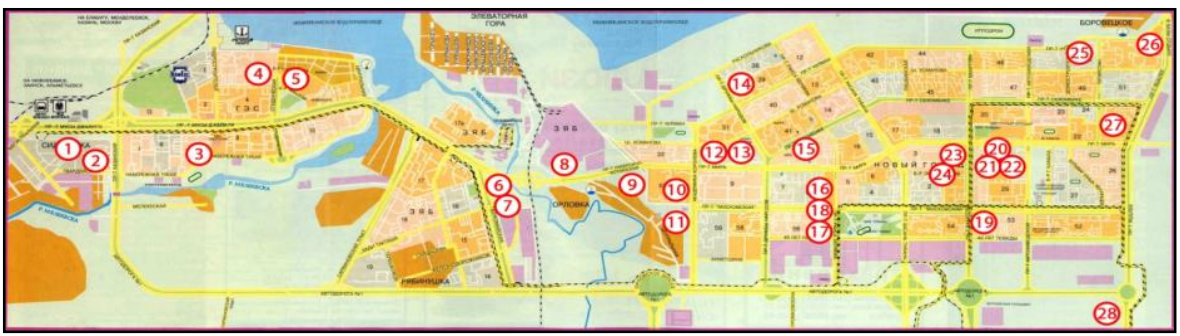

Fig. 2. Location of educational institutions of Naberezhnye Chelny.

The process of Naberezhnye Chelny transport model development is described in our early researches [11-13]. The most loaded part of the city's SRN is the central avenue Naberezhnochelninsky, which connects the old and the new parts of the city, containing 5 educational institutions. Fig. 3 shows the distribution of traffic loads in this area with existing origin-destination matrices, Fig. 4 shows the predicted values of traffic loads in the case of transition to Smart Education (red numbers indicate the number of units of private vehicles passing through these sections, and blue ones show the number of public transport passengers).

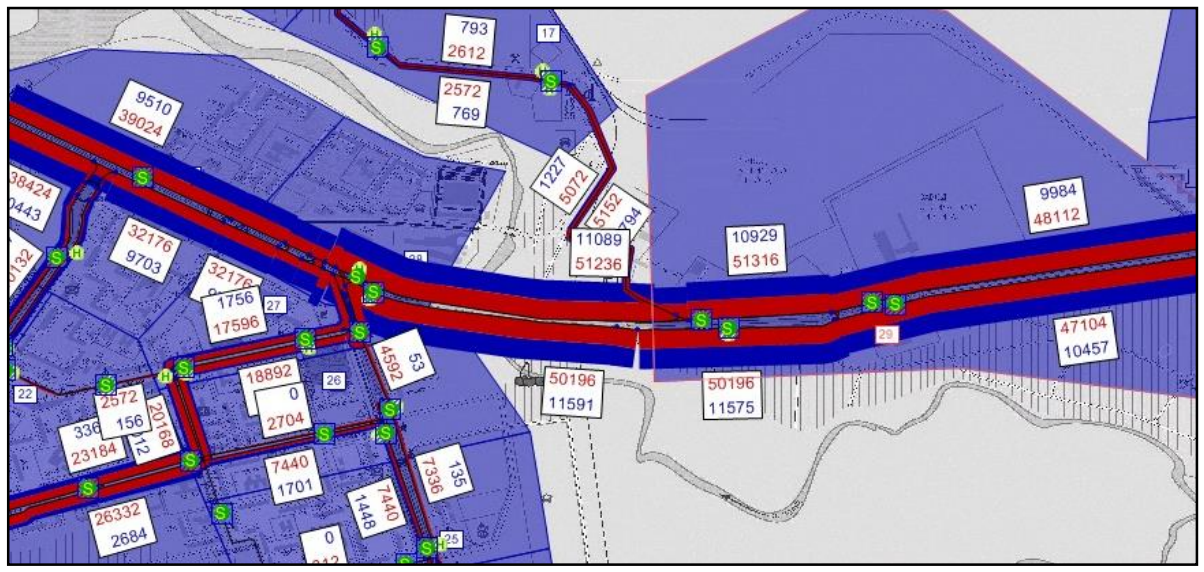

Fig. 3. Transport loads with existing origin-destination matrices.

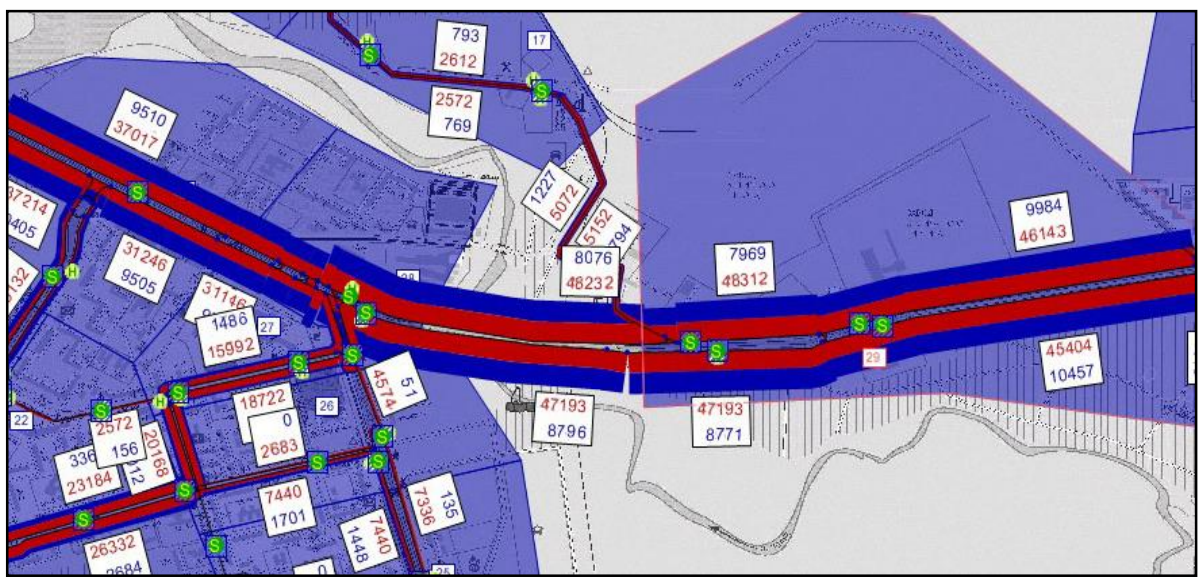

Fig. 4. Predicted transport loads in the case of transition to Smart Education. 


\section{Conclusions}

The concept of Smart Education implies, first of all, the creation of an educational system that will form not only professional competencies for future engineers, but will also develop their environmental consciousness and social responsibility for future generations. In addition, the introduction of progressive training methods can have a synergistic effect, thereby increasing the quality of processes in the manufacturing, transportation, education and other Smart City systems. Thus, on one hand, the widespread use of Blended Learning will allow transferring up to $80 \%$ of the educational process to the virtual campus, and on the other hand, to create a schedule of classroom activities in such a way that students don't make trips during peak hours. The experiment on the transport model of Naberezhnye Chelny showed that these actions can reduce traffic loads in the problem areas of the city's SRN by $3-6 \%$.

\section{References}

1. M Crang, S Graham, Sentient cities: Ambient intelligence and the politics of urban space Information, Communication \& Society, pp. 789-817 (2007)

2. J Driesen Innovation \& Education in Smart Cities; URL : http://eua.be/Libraries/uniset/uniset_ro_driesen_201611223c1167ca84b96a879ce5ff0000 9465c7.pdf?sfvrsn=0.

3. J Gabrys, Programming environments Environmentality and citizen sensing in the smart city, Environment \& Planning: Society \& Space, pp 30-48 (2014)

4. IBM. Smarter Cities. Online; URL:

http://www.ibm.com/smarterplanet/ie/en/smarter_cities/overview/[cit. 2015-12-12].

5. IEEE Smart Cities; URL: http://smartcities.ieee.org/about.html.

6. ISO (International Standardization Organization) How does your city compare to others? New ISO standard to measure up; URL : http://www.iso.org/iso/ news.htm?refidjRef1848.

7. M Lom, 0 Pribyl and M Svitek, Industry 4.0 as a Part of Smart Cities, Smart Cities Symposium, Prague, pp. 1-6 (2016)

8. M L om, 0 Prjbyl and T Zelinka, System Engineering for Smart Cities, W M SCI Orlando (2016)

9. I Makarova, R Khabibullin, A Pashkevich and A Boyko, Ensuring sustainability of the city transportation system: Problems and solutions, (ICSC) E $3 S$ W eb of Conferences, 6, paper № 02004 (2016)

10. I Makarova, R Khabibullin, A Pashkevich and K Shubenkova, Ensuring Sustainability of Public Transport System through Rational Management, Procedia Engineering, 178, pp. 137146 (2017)

11. I M akarova, R Khabibullin, A Pashkevich and K Shubenkova, Modeling as a method to improve road safety during mass events, Transportation Research Procedia, 20, pp. 430-435 (2017)

12. I M akarova, R Khabibullin, K Shubenkova and A Pashkevich, Logistical costs minimization for delivery of shot lots by using logistical information systems. Procedia Engineering, 178; pp. 330-339 (2017)

13. I M akarova, K Shubenkova, D Tikhonov and A Pashkevich, An integrated platform for blended learning in engineering education, CSEDU 2017 - Proceedings of the 9th International Conference on Computer Supported Education, 2, pp. 171-176 (2017) 
14. K Paskaleva, Enabling the smart city: The progress of e-city governance in Europe, International J ournal of Innovation and Regional Developmen, 1(4), pp. 405-422 (2009)

15. SMART CITIES STUDY: International study on the situation of ICT, innovation and Knowledge in cities; URL:

http://www.uclgdigital cities.org/app/uploads/2015/06/en_smartcitiesstudy.pdf

16. N Thrift, The sentient city and what it may portend. Big Data \& Society, 1, URL: http://dx.doi.org/10.1177/2053951714532241 (2014)

17. B W illiamson, Educating the smart city: Schooling smart citizens through computational urbanism, B ig Data \& Society, pp. 1-13 (2015) 